ARTICLE

https://doi.org/10.1038/s41467-019-13833-8

\title{
Hydroxide promotes carbon dioxide electroreduction to ethanol on copper via tuning of adsorbed hydrogen
}

\author{
Mingchuan Luo 1,3, Ziyun Wang (1) 1,3, Yuguang C. Li (1) 1,3, Jun Li (D) 1,2, Fengwang Li (1) 1, Yanwei Lum (1) 1,

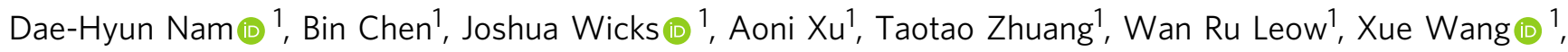

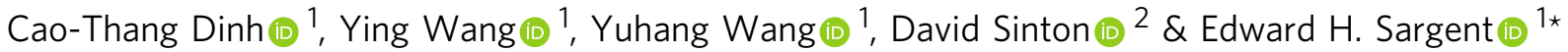

Producing liquid fuels such as ethanol from $\mathrm{CO}_{2}, \mathrm{H}_{2} \mathrm{O}$, and renewable electricity offers a route to store sustainable energy. The search for efficient electrocatalysts for the $\mathrm{CO}_{2}$ reduction reaction relies on tuning the adsorption strength of carbonaceous intermediates. Here, we report a complementary approach in which we utilize hydroxide and oxide doping of a catalyst surface to tune the adsorbed hydrogen on $\mathrm{Cu}$. Density functional theory studies indicate that this doping accelerates water dissociation and changes the hydrogen adsorption energy on $\mathrm{Cu}$. We synthesize and investigate a suite of metal-hydroxide-interface-doped-Cu catalysts, and find that the most efficient, $\mathrm{Ce}(\mathrm{OH})_{x}$-doped-Cu, exhibits an ethanol Faradaic efficiency of $43 \%$ and a partial current density of $128 \mathrm{~mA} \mathrm{~cm}^{-2}$. Mechanistic studies, wherein we combine investigation of hydrogen evolution performance with the results of operando Raman spectroscopy, show that adsorbed hydrogen hydrogenates surface ${ }^{\star} \mathrm{HCCOH}$, a key intermediate whose fate determines branching to ethanol versus ethylene.

\footnotetext{
${ }^{1}$ Department of Electrical and Computer Engineering, University of Toronto, Toronto, Ontario M5S 1A4, Canada. ${ }^{2}$ Department of Mechanical and Industria Engineering, University of Toronto, Toronto, Ontario M5S 3G8, Canada. ${ }^{3}$ These authors contributed equally: Mingchuan Luo, Ziyun Wang, Yuguang C. Li. *email: ted.sargent@utoronto.ca
} 
T he electrochemical generation of $\mathrm{C}_{2+}$ fuels and chemicals from $\mathrm{CO}_{2}$ and $\mathrm{H}_{2} \mathrm{O}$ enables the storage of intermittent renewable energy ${ }^{1-6}$. Substantial progress has been made in producing gaseous ethylene from the $\mathrm{CO}_{2}$ reduction reaction $\left(\mathrm{CO}_{2} \mathrm{RR}\right)$, and the Faradaic efficiency $(\mathrm{FE})$ now exceeds $70 \%$ at an overpotential of $0.55 \mathrm{~V}$ (ref. ${ }^{7}$ ).

By contrast, the electrochemical conversion of $\mathrm{CO}_{2}$ to liquid ethanol - a promising renewable fuel with high energy density and compatibility with existing storage and transportation infrastructure - has seen more limited progress thus far. Indeed, today's best $\mathrm{CO}_{2}$ electrocatalysts fail to provide majority ethanol production, instead preferring ethylene $e^{8-11}$

The optimization of intermediate binding energetics provides a framework in which to evaluate and design for desired electrocatalytic performance ${ }^{12,13}$. For $\mathrm{CO}_{2} \mathrm{RR}$ specifically, the binding energy of $\mathrm{CO}\left(\Delta \mathrm{E}_{\mathrm{CO}}\right)$ is an important descriptor that has enabled the prediction of a number of promising $\mathrm{CO}_{2} \mathrm{RR}$ candidates ${ }^{14}$. Experimental studies have similarly followed the correlation between adsorbed $\mathrm{CO}\left(\mathrm{CO}_{\mathrm{ad}}\right)$ as a function of alloying/doping with elements, including Zn (ref. ${ }^{15}$ ), Ag (refs ${ }^{16-18}$ ), Au (ref. ${ }^{19}$ ), $\mathrm{S}\left(\right.$ ref. ${ }^{20}$ ), $\mathrm{B}$ (ref. ${ }^{21}$ ), and $\mathrm{N}$ (ref. ${ }^{22}$ ), as well as with engineering of facets $^{23}$ and morphology $24-26$.

In spite of these impressive efforts, the $\mathrm{FE}$ of $\mathrm{CO}_{2}$-to-ethanol remains below $25 \%$ if one focuses on studies that achieve commercially-relevant current densities $\left(>100 \mathrm{~mA} \mathrm{~cm}^{-2}\right)$. Even if one includes results down to $6 \mathrm{~mA} \mathrm{~cm}^{-2}$, it has reached only $29 \% \mathrm{FE}$.

The scaling relationships among the carbonaceous intermediates ${ }^{27}$ along the multi-step reduction pathway to ethanol mean that it is difficult - if only a single site, and thus one degree of freedom, is relied upon to engineer catalyst adsorption energie s- to optimize $\Delta \mathrm{E}_{\mathrm{CO}}$ simultaneously with the initial $\mathrm{CO}_{2}$ adsorption; as well as to optimize the site for ensuing carbon-carbon coupling; and to optimize also the subsequent hydrogenation step. The formation of ethanol with high FE will rely on accessing experimental degrees of freedom that engineer these steps.

We reasoned that, since hydrogen $\left(\mathrm{H}_{\mathrm{ad}}\right)$ co-exists with carbonbased intermediates during $\mathrm{CO}_{2} \mathrm{RR}$, controlling its presence could potentially offer a new handle to help break the scaling relations. There exist hints at this possibility in the prior literature, such as in the proposed ethylene pathway in which hot water hydrogenates adsorbed ${ }^{\star} \mathrm{HCCOH}$, the penultimate reaction intermediate for both ethanol and ethylene ${ }^{28}$. Experimentally, the direct involvement of water in producing ethanol from $\mathrm{CO}_{2} \mathrm{RR}$ was clarified in a recent isotopic study ${ }^{29}$.

We, therefore, pursued means to activate near-surface water molecules with the goal of boosting the production of ethanol.
Our thinking was that cleaving the $\mathrm{Cu}-\mathrm{C}$ bond of adsorbed ${ }^{*} \mathrm{HCCOH}$ could thereby be promoted, favoring thereby the electroproduction of ethanol.

We begin with an investigation of how surface $\mathrm{H}_{\mathrm{ad}}$ affects the selectivity of $\mathrm{CO}_{2} \mathrm{RR}$ on $\mathrm{Cu}$. To this end, we designed a catalytic system that allows us to construct both hydroxide- and oxidedoped $\mathrm{Cu}$ having tunable surface $\mathrm{H}_{\mathrm{ad}}$ coverage. DFT studies reveal that this new catalyst facilitates water dissociation and favors $\mathrm{H}_{\mathrm{ad}}$ formation. We then synthesize Pourbaix-stable hydroxide-doped and oxide-doped $\mathrm{Cu}$ catalysts and investigate them both ex situ and in situ. In all cases, we achieve a notable increase in the ratio of ethanol to ethylene production, documenting fully a doubling on the doped-Cu catalysts compared to $\mathrm{Cu}$.

The best of these, $\mathrm{Ce}(\mathrm{OH})_{\mathrm{x}}$-doped-Cu, reaches a $\mathrm{FE}$ of $43 \%$ for ethanol at an operating current density of $300 \mathrm{~mA} \mathrm{~cm}^{-2}$. Mechanistic studies indicate that surface $\mathrm{H}_{\mathrm{ad}}$ favors the ethanol pathway over ethylene.

\section{Results}

DFT investigations of the effect of $\mathrm{H}_{\mathrm{ad}}$. Since $\mathrm{OH}^{-}$plays a beneficial role in promoting carbon-carbon coupling $7,30, \mathrm{CO}_{2} \mathrm{RR}$ electrocatalysis is carried out today in neutral or alkaline aqueous environment. In this environment, $\mathrm{H}_{2} \mathrm{O}$ molecules serve as the proton source for $\mathrm{CO}_{2} \mathrm{RR}$.

Cleavage of the $\mathrm{H}-\mathrm{OH}$ bond is needed to form $\mathrm{H}_{\mathrm{ad}}$ on catalytic surface - the Volmer step in the hydrogen evolution reaction, HER. This accounts for the slower HER rate in alkaline and neutral media relative to that in acidic media ${ }^{31}$. Previous studies have demonstrated that the introduction of hydroxides or oxides increases $\mathrm{H}_{\text {ad }}$ coverage by accelerating the water dissociation step ${ }^{32,33}$. The approach tunes $\mathrm{H}_{\mathrm{ad}}$ without the need to modify the bulk $\mathrm{pH}$.

We thus reasoned that doping $\mathrm{Cu}$ with a stable hydroxide or oxide could enhance the surface $\mathrm{H}_{\mathrm{ad}}$; yet allow us to maintain the alkaline environment that favors carbon-carbon coupling. We carried out DFT calculations on Ce oxide- and Mn oxide-doped$\mathrm{Cu}(111)$ (see the Methods section for details). Ce and Mn oxides were chosen due to their Pourbaix-stability under the reducing potentials used in $\mathrm{CO}_{2} \mathrm{RR}^{34}$. We examined the water dissociation energy and the $\mathrm{H}$ adsorption energy $\left(\mathrm{E}_{\mathrm{H}}\right)$ on both bare and doped-Cu(111). Figure 1 and Supplementary Fig. 1 show that water dissociation is more favorable on the oxide/hydroxidedoped-Cu surface (by $0.48 \mathrm{eV}$ and $0.39 \mathrm{eV}$ for $\mathrm{Ce}$ and $\mathrm{Mn}$ oxide, respectively) in comparison with that on the pure $\mathrm{Cu}$. The adsorption of hydrogen is also stabilized on the oxide-doped-Cu surface. $\mathrm{E}_{\mathrm{H}}$ is more favorable on $\mathrm{Mn}$ oxide/Cu than that of $\mathrm{Ce}$ oxide/ $\mathrm{Cu}$, which suggests that doping metal oxides on $\mathrm{Cu}$

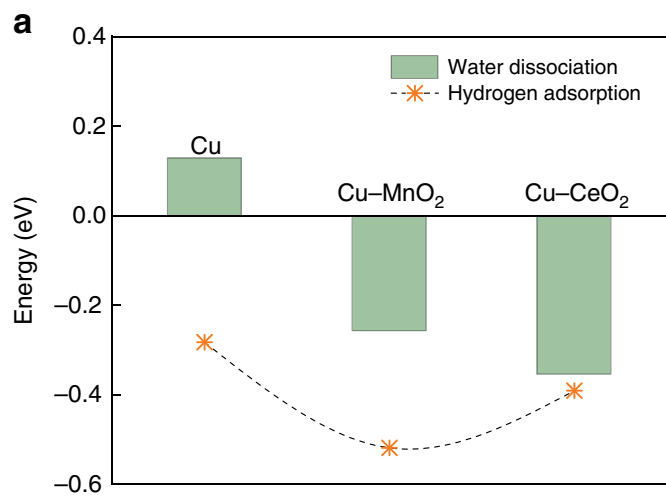

b

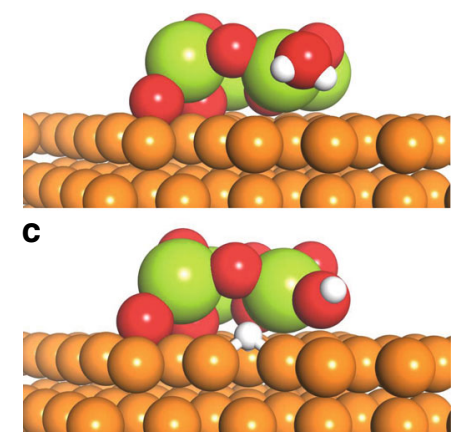

Fig. 1 Water activation on oxide-modified Cu surfaces. a Calculated water dissociation reaction energies and hydrogen adsorption energies on various surfaces. $\mathbf{b}$ Surface configurations of $\mathrm{CeO}_{2} / \mathrm{Cu}$ with and $\mathbf{c}$ without adsorbed hydrogen. 
provides the mean to control the extent of local $\mathrm{H}_{\mathrm{ad}}$. These findings suggested that building such hybrid catalysts could enable us to investigate and exploit $\mathrm{H}_{\mathrm{ad}}$ in $\mathrm{CO}_{2} \mathrm{RR}$.

Catalyst synthesis and characterization. To synthesize the hybrid catalysts, we began with $\mathrm{Cu}$-sputtered-polytetrafluoroethylene $(\mathrm{Cu} /$ PTFE) as the substrate ${ }^{7}$, and we deposited either hydroxides or oxides via electrochemical or sputtering methods (Methods). The electrochemical deposition of metallic hydroxide was carried out in a neutral electrolyte containing the corresponding metallic nitrate as the precursor ${ }^{35}$ (Supplementary Fig. 2). A cathodic current was first applied to the $\mathrm{Cu} / \mathrm{PTFE}$ electrode to generate $\mathrm{OH}^{-}$from nitrate reduction. The metallic hydroxide was then deposited onto the $\mathrm{Cu}$ surface via chemical reaction between the metallic cation and locally-generated $\mathrm{OH}^{-}$. During the electrochemical deposition, the color of the $\mathrm{Cu}$ surface turned to brown.

To understand the nature of the doped hydroxides, we carried out characterization of the cerium hydroxide-doped-Cu/PTFE sample (denoted $\left.\mathrm{Ce}(\mathrm{OH})_{\mathrm{x}} / \mathrm{Cu} / \mathrm{PTFE}\right)$ using scanning electron microscopy (SEM), transmission electron microscopy (TEM) and scanning transmission electron microscopy (STEM), as well as Xray diffraction (XRD) and X-ray photoelectron spectroscopy (XPS). Figure 2a shows the typical 3-dimensional networked structure after $\mathrm{Ce}(\mathrm{OH})_{\mathrm{x}}$ (Fig. 2a) electrochemically deposited into $\mathrm{Cu} / \mathrm{PTFE}$ fibers. We propose that this structure facilitates $\mathrm{CO}_{2}$ gas penetration to the triple-phase reaction region. STEM elemental mapping shows a homogeneous distribution of $\mathrm{Cu}$ and $\mathrm{Ce}$ throughout a single fiber (Fig. 2b). High-magnification SEM images of $\mathrm{Ce}(\mathrm{OH})_{\mathrm{x}} / \mathrm{Cu} / \mathrm{PTFE}$ further reveal substantially uniformly-decorated nano-islands on the surface (Fig. 2c) with an average size of $18 \mathrm{~nm}$ and a typical range of $6-30 \mathrm{~nm}$ (Supplementary Fig. 3). High-resolution TEM reveals the interface between $\mathrm{Ce}(\mathrm{OH})_{\mathrm{x}}$ and $\mathrm{Cu} / \mathrm{PTFE}$ (Fig. 2d). The corresponding Fast Fourier Transform (FFT, the inset of Fig. 2d) pattern matches that of $\mathrm{Cu}_{2} \mathrm{O}$ (111), indicating that the $\mathrm{Cu} / \mathrm{PTFE}-$ based sample was partially oxidized. The oxidation of $\mathrm{Cu}$ is also seen in the XRD patterns of Cu/PTFE (Supplementary Fig. 4a), in which the diffraction peaks corresponding to both $\mathrm{Cu}$ and $\mathrm{Cu}_{2} \mathrm{O}$ are observed.

The absence of observable lattice spacings in HRTEM, and a corresponding lack of crystalline peaks in XRD, suggest that the electrochemically-deposited $\mathrm{Ce}(\mathrm{OH})_{\mathrm{x}}$ exists in an amorphous structure, in agreement with the previous reports ${ }^{35}$. Highresolution XPS spectra for the $\mathrm{Cu} 2 p$ region further show the co-existence of both metallic and oxidized states (Supplementary Fig. $4 \mathrm{~b})$. The Ce $3 d$ spectra shows the co-existence of $\mathrm{Ce}^{4+}$ and $\mathrm{Ce}^{3+}$, indicating that the deposition of cerium species (Supplementary Fig. 4c, d) was indeed achieved. The $\mathrm{O}$ 1s spectra confirm that the cerium species exist as hydroxide (Supplementary Fig. 4e).

Since the chemical states of metals are dependent on the applied potential ${ }^{36}$, we carried out operando X-ray adsorption spectroscopy (XAS) to monitor the oxidation states of $\mathrm{Cu}$ and $\mathrm{Ce}$ during $\mathrm{CO}_{2} \mathrm{RR}$ electrocatalysis by looking into the $\mathrm{Cu} \mathrm{K}$-edge and $\mathrm{Ce}_{3}$-edge, respectively. We found that - in agreement with the XPS results $-\mathrm{Cu}$ species were slightly oxidized before the reaction (Fig. 2e, Supplementary Fig. 5). However, once a negative potential had been applied during $\mathrm{CO}_{2} \mathrm{RR}$, only peaks corresponding to metallic Cu were observed (Supplementary Fig. 5). No change of $\mathrm{Cu}$ local structure (i.e., oxidation state, coordination number, and bond distance) was observed throughout $\mathrm{CO}_{2} \mathrm{RR}$ process $^{37}$ (Supplementary Fig. 6 and Supplementary Table 1). Fig. $2 \mathrm{f}$ shows that, once a potential of $-0.57 \mathrm{~V}$ vs. RHE was applied, the chemical state of $\mathrm{Ce}$ underwent an initial reduction. The ratio of $\mathrm{Ce}^{3+} / \mathrm{Ce}^{4+}$ slightly increased from $-0.57 \mathrm{~V}$ to -0.64 $\mathrm{V}$ vs. RHE, after which it remained unchanged upon furtherincreased reducing potentials. We conclude that an interface is a

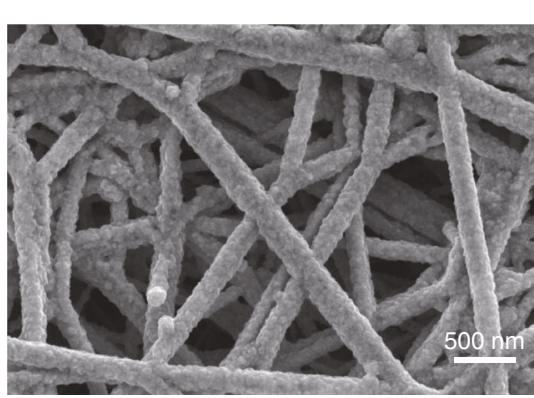

b

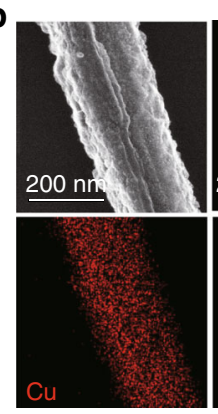

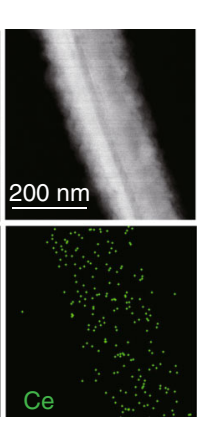

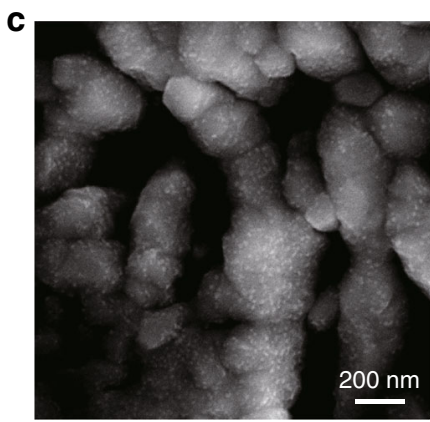

d

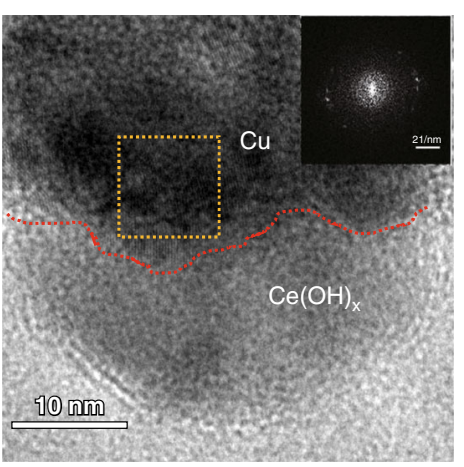

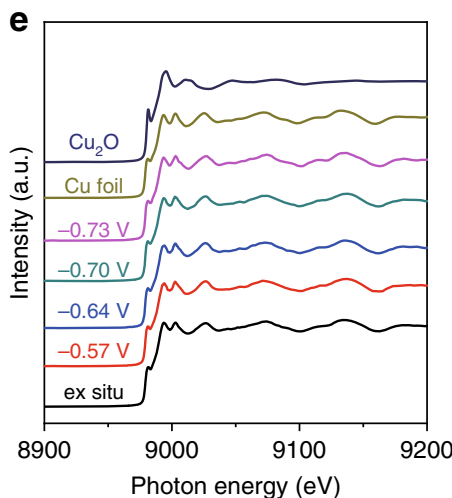

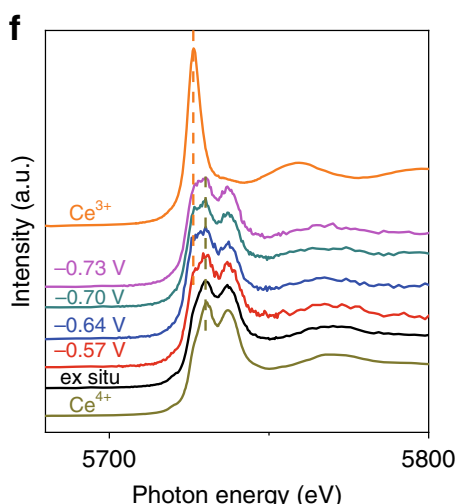

Fig. 2 Structural characterization of $\mathbf{C e}(\mathbf{O H})_{\mathbf{x}}$ modified $\mathbf{C u}$ catalysts. a Scanning electron microscope image, b STEM image and corresponding EDX mapping for $\mathrm{Cu}$ and $\mathrm{Ce}$, $\mathbf{c}$ High-magnitude SEM image, $\mathbf{d}$ High-resolution transmission electron microscopy image of $\mathrm{Ce}(\mathrm{OH})_{x} / \mathrm{Cu} / \mathrm{PTFE}$. The red dashed

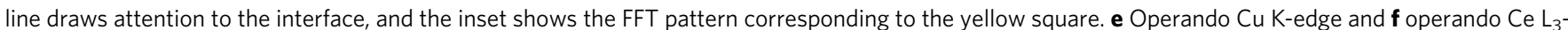
edge XAS of $\mathrm{Ce}(\mathrm{OH})_{x} / \mathrm{Cu} /$ PTFE catalyst under a number of operating potentials in a flow cell. 

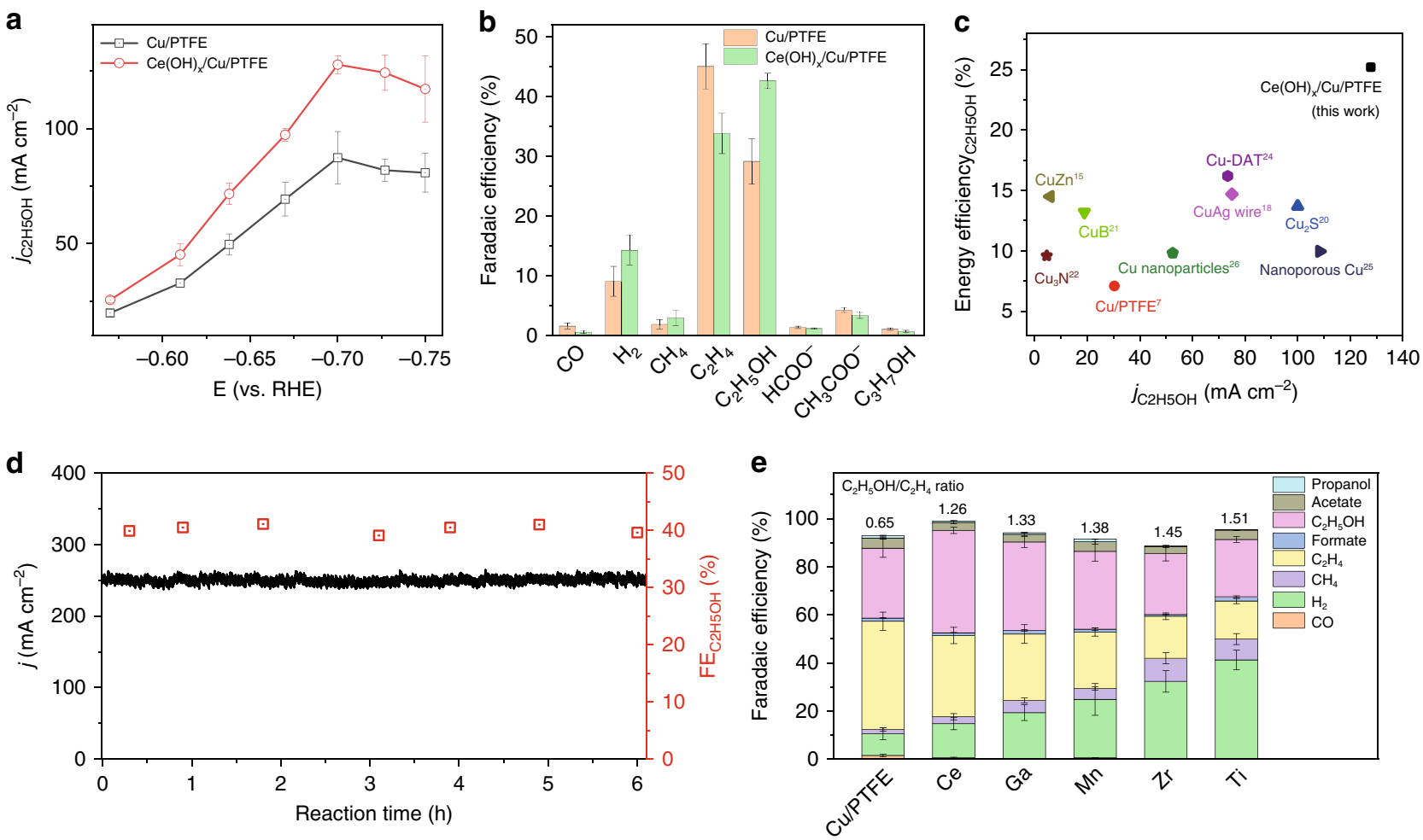

Fig. 3 Carbon dioxide electroreduction performance. a Partial ethanol current density of $\mathrm{Ce}(\mathrm{OH})_{x} / \mathrm{Cu} / \mathrm{PTFE}$ and bare $\mathrm{Cu} / \mathrm{PTFE}$ under various potentials. b Product distribution of $\mathrm{Ce}(\mathrm{OH})_{x} / \mathrm{Cu} / \mathrm{PTFE}$ and bare $\mathrm{Cu} / \mathrm{PTFE}$ at the $-0.7 \mathrm{~V}$ versus RHE. c Energy efficiency as a function of partial current density on Ce $(\mathrm{OH})_{x} / \mathrm{Cu} / \mathrm{PTFE}$, in comparison with other reports with operational current density higher than $10 \mathrm{~mA} \mathrm{~cm}^{-2}$. d i-t curve (left axis) of $\mathrm{Ce}(\mathrm{OH})_{x} / \mathrm{Cu} / \mathrm{PTFE}$ catalyst along with corresponding Faradaic efficiency of ethanol (right axis). e Product distribution of various hydroxides/oxides modified Cu/PTFE electrode, along with corresponding $\mathrm{C}_{2} \mathrm{H}_{5} \mathrm{OH} / \mathrm{C}_{2} \mathrm{H}_{4}$ ratio. The error bars represent the standard deviation from at least three independent tests.

provided between metallic $\mathrm{Cu}$ and oxidized $\mathrm{Ce}$ under the reducing conditions applied during $\mathrm{CO}_{2} \mathrm{RR}$ electrocatalysis.

$\mathrm{CO}_{2} \mathrm{RR}$ performance. Having established the structural properties of the $\mathrm{Ce}(\mathrm{OH})_{\mathrm{x}} / \mathrm{Cu} / \mathrm{PTFE}$ catalyst, we then assessed its $\mathrm{CO}_{2} \mathrm{RR}$ performance. We used a flow cell set-up with $1 \mathrm{M} \mathrm{KOH}$ solution as the electrolyte and throughout included controls involving bare $\mathrm{Cu} / \mathrm{PTFE}$ (Supplementary Fig. 7 and Supplementary Tables 2-5).

The FE for ethanol reached $43 \%$ when the $\mathrm{Ce}(\mathrm{OH})_{\mathrm{x}} / \mathrm{Cu} / \mathrm{PTFE}$ catalyst was employed - well above the value of $29 \%$ for the $\mathrm{Cu}$ control. The $\mathrm{Ce}(\mathrm{OH})_{\mathrm{x}} / \mathrm{Cu} / \mathrm{PTFE}$ catalyst also achieved an impressive partial current density, $128 \mathrm{~mA} \mathrm{~cm}^{-2}$ (Fig. 3a), for ethanol, compared to $87 \mathrm{~mA} \mathrm{~cm}^{-2}$ for the copper control. By comparing the product distributions at the optimal potentials, we found that $\mathrm{Ce}(\mathrm{OH})_{\mathrm{x}}$ doping had increased the $\mathrm{FE}$ toward $\mathrm{H}_{2}$ by $5 \%$ compared to the $\mathrm{Cu} / \mathrm{PTFE}$ baseline (Fig. 3b). This is consistent with DFT results that indicate that surface $\mathrm{H}_{\mathrm{ad}}$ is enhanced via accelerated water dissociation and optimized hydrogen adsorption. The ethanol:ethylene ratio increased from $0.65(\mathrm{Cu} / \mathrm{PTFE})$ to $1.26\left(\mathrm{Ce}(\mathrm{OH})_{\mathrm{x}} / \mathrm{Cu} / \mathrm{PTFE}\right)$, which is the highest among electrocatalysts that achieve a current density of $>6 \mathrm{~mA}$ $\mathrm{cm}^{-2}$ (Supplementary Table 2). The energy efficiency as a function of partial current density for ethanol (Fig. 3c) reveals that the $\mathrm{Ce}(\mathrm{OH})_{\mathrm{x}} / \mathrm{Cu} / \mathrm{PTFE}$ achieved an energy efficiency of $25 \%$. This is, by a factor of 1.6, the highest reported for systems operating above $10 \mathrm{~mA} \mathrm{~cm}^{-2}$ (Supplementary Table 6).

We also evaluated operating stability of the $\mathrm{Ce}(\mathrm{OH})_{\mathrm{x}} / \mathrm{Cu} / \mathrm{PTFE}$ catalyst. It provided stable operation over an initial $6 \mathrm{~h}$ at current density $250 \mathrm{~mA} \mathrm{~cm}^{-2}$ (Fig. 3d). TEM and SEM images of Ce $(\mathrm{OH})_{\mathrm{x}} / \mathrm{Cu} / \mathrm{PTFE}$ electrode after reaction showed the preservation of the hydroxide/ $\mathrm{Cu}$ interface, as well as of the well-dispersed $\mathrm{Ce}$
$(\mathrm{OH})_{\mathrm{x}}$ nano-islands on the sputtered $\mathrm{Cu}$ surface (Supplementary Fig. 8).

We used labeled ${ }^{13} \mathrm{CO}_{2}$ and confirmed that the ethanol was produced from $\mathrm{CO}_{2}$. This test indicates that ethanol contamination is not a source of artefactual ethanol (Supplementary Fig. 9a). The small changes (within 3\%) in electrochemically active surface area (ECSA) of the $\mathrm{Cu} / \mathrm{PTFE}$ before and after the deposition of $\mathrm{Ce}$ $(\mathrm{OH})_{\mathrm{x}}$ also excluded the influence of surface area differences on electrocatalytic performance (Supplementary Fig. 9b-d). Due to its electrical insulation, the PTFE substrate is not expected to affect ECSA measurements.

To investigate whether the materials design strategy herein offers a general way to tune $\mathrm{CO}_{2} \mathrm{RR}$ selectivity, we further tested other stable hydroxide- and oxide-doped $\mathrm{Cu}$ catalysts including $\mathrm{Ga}(\mathrm{OH})_{3}$, $\mathrm{Mn}(\mathrm{OH})_{3}, \mathrm{Zr}(\mathrm{OH})_{4}$ and $\mathrm{TiO}_{2}$ (ref. $\left.{ }^{34}\right)$. A suite of microscopy and spectroscopy analysis confirmed they are structurally analogous with $\mathrm{Ce}(\mathrm{OH})_{\mathrm{x}} / \mathrm{Cu} / \mathrm{PTFE}$ (Supplementary Figs. 10-13). Similar electrocatalytic behaviors were observed in the doped samples: compared to $\mathrm{Cu} / \mathrm{PTFE}$ controls, $\mathrm{H}_{2}$ and $\mathrm{CH}_{4}$ production increased, and $\mathrm{C}_{2} \mathrm{H}_{4}$ decreased (Fig. 3e). A positive correlation was observed between the FE ratio of ethanol/ethylene and the $\mathrm{FE}$ of $\mathrm{H}_{2}\left(\mathrm{FE}_{\mathrm{H} 2}\right)$, with $\mathrm{TiO}_{2} / \mathrm{Cu}$ / PTFE exhibiting the highest ethanol/ethylene ratio of 1.51 . This agrees with the hypothesis that enhanced $\mathrm{H}_{\mathrm{ad}}$ promotes ethanol over ethylene. The HER activities of the samples evaluated using the same flow cell system in $\mathrm{Ar}$ atmosphere showed the same trend as the $\mathrm{FE}_{\mathrm{H} 2}$ during $\mathrm{CO}_{2} \mathrm{RR}$; i.e., $\mathrm{TiO}_{2} / \mathrm{Cu} / \mathrm{PTFE}>\mathrm{Zr}(\mathrm{OH})_{4} / \mathrm{Cu} /$ $\mathrm{PTFE}>\mathrm{Mn}(\mathrm{OH})_{3} / \mathrm{Cu} / \mathrm{PTFE}>\mathrm{Ga}(\mathrm{OH})_{3} / \mathrm{Cu} / \mathrm{PTFE}>\mathrm{Ce}(\mathrm{OH})_{\mathrm{x}} / \mathrm{Cu} /$ PTFE, further confirming the enhanced $\mathrm{H}_{\mathrm{ad}}$ on $\mathrm{Cu}$ due to an accelerated Volmer step (Supplementary Fig. 14).

Mechanistic studies. We then sought further mechanistic insight into the selectivity of $\mathrm{CO}_{2} \mathrm{RR}$. Goddard and co-workers ${ }^{28,38}$ have 


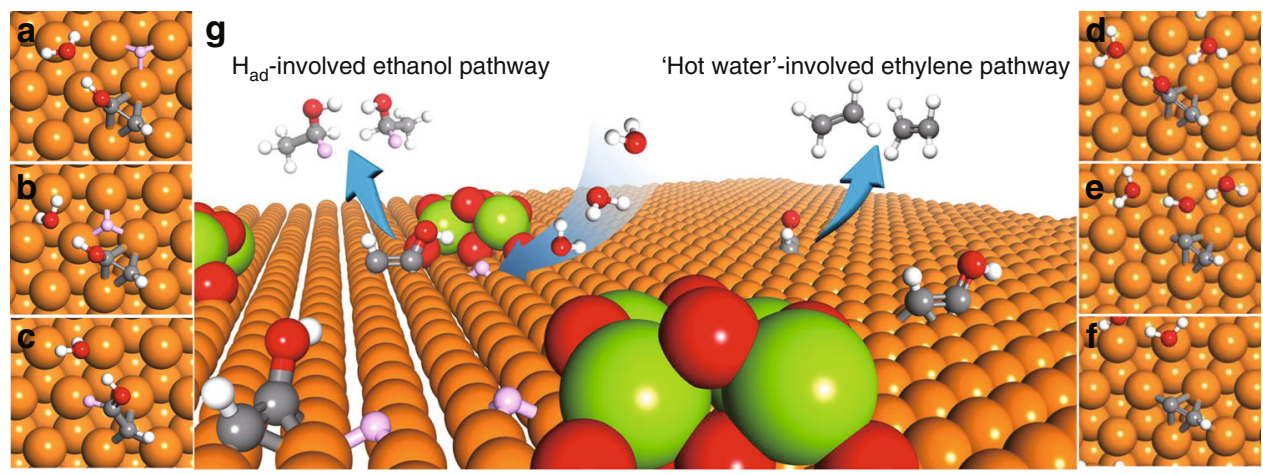

Fig. 4 Density functional theory calculations on the ethylene and ethanol pathways. Top views of geometries $\mathbf{a}$ initial state, $\mathbf{b}$ transition state, and $\mathbf{c}$ final state of key reaction towards ethanol, and $\mathbf{d}$ initial state, $\mathbf{e}$ transition state, and $\mathbf{f}$ final state of key reaction towards ethylene. Red, white, gray and orange balls stand for oxygen, hydrogen, carbon, and copper, respectively, while pink balls stand for $\mathrm{H}_{\mathrm{ad}}$ on $\mathrm{Cu}$.

previously shown that a key intermediate in the branching of ethylene vs. ethanol is ${ }^{*} \mathrm{HCCOH}$ (Fig. 4a, d). The ethylene pathway was proposed to be related to the removal of $\mathrm{OH}$ in ${ }^{\star} \mathrm{HCCOH}$ (Fig. 4e) form ${ }^{*} \mathrm{CCH}$ (Fig. $4 \mathrm{f}$ ); from which ${ }^{*} \mathrm{CCH}$ is then further hydrogenated, generating ethylene. In contradistinction, ${ }^{\star} \mathrm{HCCOH}$ is hydrogenated into ${ }^{*} \mathrm{HCCHOH}$ (Fig. $4 \mathrm{a}-\mathrm{c}$ ) in the ethanol pathway.

As seen in Fig. 4d-f, surface water molecules are involved in the removal of $\mathrm{OH}$ : the hydroxyl group in ${ }^{*} \mathrm{HCCOH}$ is surrounded by five other water molecules with hydrogen bonds. In the transition state, the $\mathrm{O}-\mathrm{C}$ bond between the hydroxyl group and ${ }^{*} \mathrm{CCH}$ dissociates with the help of surface water. In the final state, $\mathrm{OH}$ is stabilized by water and ${ }^{*} \mathrm{CCH}$ is formed. Thus, surface water plays an important role in the ethylene pathway. In the ethanol pathway, the $\mathrm{H}_{\mathrm{ad}}$ attacks the ${ }^{\star} \mathrm{HCCOH}$ (Fig. 4b), forming ${ }^{*} \mathrm{HCCHOH}$, the key intermediate towards ethanol. $\mathrm{H}_{\text {ad }}$ is only involved in the branching reaction towards ethanol. When we enhance $\mathrm{H}_{\mathrm{ad}}$ coverage, ethanol selectivity is enhanced (Fig. 4g).

To probe experimentally whether hydroxide modification also impacts the adsorption of carbonaceous intermediates on $\mathrm{Cu}$, we carried out in situ Raman measurements and compared bare $\mathrm{Cu} /$ PTFE with $\mathrm{Ce}(\mathrm{OH})_{\mathrm{x}} / \mathrm{Cu} / \mathrm{PTFE}$ across the potential region -0.24 to $-0.73 \mathrm{~V}$ under $\mathrm{CO}_{2} \mathrm{RR}$ (Supplementary Fig. 15). Due to their short life time, we are unable to provide direct experimental evidence for the ${ }^{\star} \mathrm{HCCOH}$ intermediates; however, we found negligible influence of $\mathrm{Ce}(\mathrm{OH})_{\mathrm{x}}$ on adsorbed $\mathrm{CO}\left(\mathrm{CO}_{\mathrm{ad}}\right)-$ the Raman shift of frustrated rotation, and stretching, associated with $\mathrm{Cu}-\mathrm{CO}$, remained in the same position after $\mathrm{Ce}(\mathrm{OH})_{\mathrm{x}}$-modification of the $\mathrm{Cu}$ surface. Given the scaling relationship between $\mathrm{CO}_{\mathrm{ad}}$ and other carbonaceous intermediates ${ }^{14}$, we deduced that the electrocatalytic differences between bare Cu/PTFE and Ce $(\mathrm{OH})_{\mathrm{x}} / \mathrm{Cu} / \mathrm{PTFE}$ were unlikely to have originated from changes in the adsorption of carbonaceous species.

It is worth noting that the hydroxide deposition on $\mathrm{Cu}$ also promotes the $\mathrm{CH}_{4}$ production from $\mathrm{CO}_{2} \mathrm{RR}$. Buonsanti and coworkers ${ }^{39}$ recently reported the colloidal synthesis of a class of $\mathrm{Cu} / \mathrm{CeO}_{2-\mathrm{x}}$ heterodimers that showed a $\mathrm{CO}_{2}$-to- $\mathrm{CH}_{4} \mathrm{FE}$ of $54 \%$ in $\mathrm{KHCO}_{3}$ solution, exceeding the physically-mixed and individual controls. With the aid of DFT studies, they assigned the enhanced $\mathrm{CH}_{4}$ production to the interface comprised of $\mathrm{Cu}, \mathrm{Ce}$, and $\mathrm{O}-$ vacancy sites that enabled breaking of the $\mathrm{CHO}^{*} / \mathrm{CO}^{*}$ scaling relation. This mechanism investigated herein may contain analogies with how the hydroxide/ $\mathrm{Cu}$ interface promotes $\mathrm{CH}_{4}$ production through the $\mathrm{C} 1$ pathway.

\section{Discussion}

In summary, we reported an approach to higher-efficiency $\mathrm{CO}_{2}{ }^{-}$ to-ethanol conversion levering tuning of the adsorption of hydrogen on $\mathrm{Cu}$. The cerium hydroxide-doped copper catalyst provided a $43 \% \mathrm{FE}$ at a total current density of $300 \mathrm{~mA} \mathrm{~cm}^{-2}$. Mechanistic studies indicated that $\mathrm{H}_{\mathrm{ad}}$ on $\mathrm{Cu}$ favors the ethanol over the ethylene pathway by attacking the $\mathrm{Cu}-\mathrm{C}$ bond of the ${ }^{*} \mathrm{HCCOH}$ intermediate. The findings suggest further avenues to engineer hybrid catalysts that contribute multiple degrees of freedom to the design of multi-step $\mathrm{CO}_{2}$ reduction reactions.

\section{Methods}

Electrode preparation. $\mathrm{Cu} / \mathrm{PTFE}$ electrodes were prepared by sputtering a $\mathrm{Cu}$ layer of $300 \mathrm{~nm}$ in thickness onto a PTFE membrane (average pore size of $450 \mathrm{~nm}$ ) using a Cu target $(99.99 \%)$ at a rate of $1 \AA \mathrm{s}^{-1}$.

Using the $\mathrm{Cu} / \mathrm{PTFE}$ as the substrate, we electrochemically deposited various hydroxides in a three-electrode electrochemical cell. A potentiostat (MetrohmAutolab, PGSTAT204) was used for the electrodeposition. The Cu/PTFE, a platinum foil and an $\mathrm{Ag} / \mathrm{AgCl}$ electrode (saturated with $\mathrm{KCl}$ ) were used as the working, counter and reference electrodes, respectively. The electrodeposition solution comprised $0.1 \mathrm{M} \mathrm{KCl}$ as the supporting electrolyte, and $0.025 \mathrm{M}$ corresponding nitrate salts (cerium nitrate, 99.99\%, Sigma-Aldrich; gallium nitrate, 99.9\%, SigmaAldrich; zirconium oxynitrate, $99.99 \%$, Sigma-Aldrich; manganese nitrate, $99.99 \%$, Sigma-Aldrich) as the precursor. A current density of $-0.5 \mathrm{~mA} \mathrm{~cm}^{-2}$ was held for a defined length of time $(10,20,30,40$, and $50 \mathrm{~min})$ to achieve varied surface coverage of hydroxides. Following the completion of the deposition, the working electrode was rinsed with DI water for at least three times and subsequently dried in $\mathrm{N}_{2}$ atmosphere. Due to the instability of titanium nitrate, we deposited titanium oxides onto $\mathrm{Cu} / \mathrm{PTFE}$ via a sequential sputtering of $\mathrm{Cu}$ followed by a layer of $\mathrm{TiO}_{2}(5 \mathrm{~nm})$.

Materials characterization. The morphology of the electrodes was characterized using scanning electron microscopy (SEM, Hitachi S-5200) with a $5-\mathrm{kV}$ beam voltage. Transmission electron microscopy (TEM) and elemental mapping images were collected using a Hitachi HF-3300, at an acceleration voltage of $300 \mathrm{kV}$, equipped with a Bruker energy dispersive X-ray spectroscopy (EDX) detector. The acquisition time in the EDX studies was 3 min. Powder X-ray diffraction (XRD) patterns were recorded using a Bruker $\mathrm{D} 8$ using $\mathrm{Cu}-\mathrm{Ka}$ radiation $(\lambda=0.15406 \mathrm{~nm})$, $\mathrm{X}$-ray photoelectron spectroscopy (XPS) was conducted on a PHI 5700 ESCA System using Al Ka X-ray radiation $(1486.6 \mathrm{eV})$ for excitation. Operando X-ray absorption spectroscopy (XAS) investigations were carried out at the 9BM beamline of the Advanced Photon Source (APS) located in the Argonne National Laboratory (Lemont, IL). Detailed information regarding operando XAS tests in flow cells is available in a previous report ${ }^{37} \cdot \mathrm{Cu}_{2} \mathrm{O}, \mathrm{Cu}$ foil, cerium oxide, and cerium oxalate hydrate were used as the reference samples. In situ Raman measurements were performed on a Renishaw inVia Raman Microscope in a modified flow cell and a water immersion objective $(\times 63)$ with a $785 \mathrm{~nm}$ laser, using a $5 \mathrm{~s}$ integration and averaging 20 scans per region. In the above systems, platinum wire and an $\mathrm{Ag} / \mathrm{AgCl}$ electrode were used as the counter and reference electrode, respectively.

Electrochemical measurements. Electrochemical studies were carried out using an electrochemical flow cell consisting of a gas chamber, a cathodic chamber, and an anodic chamber. The PTFE-based working electrode was fixed between the gas and cathodic chambers, with the catalysts layer side facing the cathodic chamber (geometric active surface area of $1 \mathrm{~cm}^{2}$ ). An anion exchange membrane (Fumasep FAA-3-PK-130) was used to separate the anodic and cathodic chambers. All electrochemical tests were conducted on an Autolab PGSTAT204, with an Ag/AgCl electrode and $\mathrm{Ni}$ foam being the reference and counter electrodes, respectively. Potentials were converted to the reversible hydrogen electrode scale after iR 
correction. Electrochemical impedance spectroscopy (EIS) in the frequency range of $10^{5}-10^{-1} \mathrm{~Hz}$ and an amplitude of $10 \mathrm{mV}$ was used to determine the $\mathrm{R}$ value.

For performance studies, $1 \mathrm{M} \mathrm{KOH}$ was used as the electrolyte, and it was circulated through the cathodic and anodic chambers using peristaltic pumps at a rate of $10 \mathrm{~mL} \mathrm{~min}^{-1}$. The flow rate of $\mathrm{CO}_{2}$ gas through the gas chamber was controlled to be $50 \mathrm{sccm}$ using a digital gas flow controller. Gas chromatography (PerkinElmer Clarus 600) with a flame ionization detector (FID) and a thermal conductivity detector (TCD) was used to analyze the gas products, collected from the end of the gas chamber. ${ }^{1} \mathrm{H}$ NMR spectroscopy $(600 \mathrm{MHz}$, Agilent DD2 NMR Spectrometer) with water suppression was used to analyze the liquid products, using $\mathrm{D}_{2} \mathrm{O}$ and DMSO as the lock solvent and internal reference, respectively. The hydrogen evolution reaction (HER) activities of various electrodes were evaluated in the same flow cell system, with the flow gas changed from $\mathrm{CO}_{2}$ to Ar.

DFT calculations. All DFT calculations were carried out using the Vienna ab initio simulation program (VASP; https://vasp.at/ $/)^{40-43}$. The projected augmented wave approach $^{44,45}$ was used to describe the electron-ion interactions with cutoff energy at $450 \mathrm{eV}$. The generalized gradient approximation with the Perdew, Burke and Ernzerhof exchange correlation functional was used ${ }^{46}$. For all the cerium related calculations, due to the strong correlations of the partially filled Ce $4 \mathrm{f}$ states, we employed the Hubbard parameter, $\mathrm{U}$, to illustrate the on-site coulombic interaction $^{47}$. A U-J value of $4.5 \mathrm{eV}$ was chosen for Ce according to a previous study ${ }^{48}$. In order to illustrate the long-range dispersion interactions between the adsorbates and catalysts, we employed the D3 correction method by Grimme et al. ${ }^{49}$. Brillouin zone integration was accomplished using a $3 \times 3 \times 1$ Monkhorst-Pack k-point mesh. Four layers of $\mathrm{Cu}(111)$ surface was optimized, with the top 2 layers relaxed and bottom 2 layers fixed. Two molecular units of $\mathrm{CeO}_{2}$ were introduced on to the $\mathrm{Cu}$ surface and optimized. To keep the model consistent, we replaced Ce atoms with $\mathrm{Mn}$ atoms and re-optimized the structure for the $\mathrm{Mn}$ oxide calculations. The water dissociation energy was calculated using $\mathrm{E}_{\text {dissociation }}=\mathrm{E}_{\mathrm{H}_{2} \mathrm{O}^{*}}-\mathrm{E}_{\mathrm{H}_{*}+\mathrm{OH} *}$, and the hydrogen adsorption energy was calculated using $\mathrm{E}_{\mathrm{H} \mathrm{d}}=\mathrm{E}_{\mathrm{H}^{*}}+\mathrm{E}_{\text {slab }}-0.5 \mathrm{E}_{\mathrm{H}_{2}}$, where ${ }^{*}$ designates a surface adsorbed specie.

\section{Data availability}

The data that support the findings of this study are available from the corresponding author on reasonable request.

Received: 8 May 2019; Accepted: 26 November 2019;

Published online: 20 December 2019

\section{References}

1. Gao, S. et al. Partially oxidized atomic cobalt layers for carbon dioxide electroreduction to liquid fuel. Nature 529, 68-71 (2016).

2. Schreier, M. et al. Solar conversion of $\mathrm{CO}_{2}$ to $\mathrm{CO}$ using earth-abundant electrocatalysts prepared by atomic layer modification of CuO. Nat. Energy 2 , 17087-17096 (2017).

3. Mariano, R. G., McKelvey, K., White, H. S. \& Kanan, M. W. Selective increase in $\mathrm{CO}_{2}$ electroreduction activity at grain-boundary surface terminations. Science 358, 1187-1192 (2017).

4. Appel, A. M. et al. Frontiers, opportunities, and challenges in biochemical and chemical catalysis of $\mathrm{CO}_{2}$ fixation. Chem. Rev. 113, 6621-6658 (2013).

5. Liu, M. et al. Enhanced electrocatalytic $\mathrm{CO}_{2}$ reduction via field-induced reagent concentration. Nature 537, 382-386 (2016).

6. Mistry, H., Varela, A. S., Kühl, S., Strasser, P. \& Cuenya, B. R. Nanostructured electrocatalysts with tunable activity and selectivity. Nat. Rev. Mater. 1, 16009-16023 (2016).

7. Dinh, C. T. et al. $\mathrm{CO}_{2}$ electroreduction to ethylene via hydroxide-mediated copper catalysis at an abrupt interface. Science 360, 783-787 (2018).

8. Schouten, K. J., Calle-Vallejo, F. \& Koper, M. T. A step closer to the electrochemical production of liquid fuels. Angew. Chem. Int. Ed. 53, 10858-10860 (2014).

9. Verma, S., Kim, B., Jhong, H. R., Ma, S. \& Kenis, P. J. A gross-margin model for defining technoeconomic benchmarks in the electroreduction of $\mathrm{CO}_{2}$. ChemSusChem 9, 1972-1979 (2016).

10. Bushuyev, O. S. et al. What should we make with $\mathrm{CO}_{2}$ and how can we make It? Joule 2, 825-832 (2018).

11. Spurgeon, J. M. \& Kumar, B. A comparative technoeconomic analysis of pathways for commercial electrochemical $\mathrm{CO}_{2}$ reduction to liquid products. Energy Environ. Sci. 11, 1536-1551 (2018).

12. Seh, Z. W. et al. Combining theory and experiment in electrocatalysis: Insights into materials design. Science 355, eaad4998 (2017).

13. Norskov, J. K., Bligaard, T., Rossmeisl, J. \& Christensen, C. H. Towards the computational design of solid catalysts. Nat. Chem. 1, 37-46 (2009).

14. Liu, X. et al. Understanding trends in electrochemical carbon dioxide reduction rates. Nat. Commun. 8, 15438-15445 (2017).
15. Ren, D., Ang, B. S.-H. \& Yeo, B. S. Tuning the selectivity of carbon dioxide electroreduction toward ethanol on oxide-derived $\mathrm{Cu}_{\mathrm{x}} \mathrm{Zn}$ Catalysts. ACS Catal. 6, 8239-8247 (2016).

16. Lee, S., Park, G. \& Lee, J. Importance of Ag-Cu biphasic boundaries for selective electrochemical reduction of $\mathrm{CO}_{2}$ to ethanol. ACS Catal. 7 , 8594-8604 (2017).

17. Clark, E. L., Hahn, C., Jaramillo, T. F. \& Bell, A. T. Electrochemical $\mathrm{CO}_{2}$ reduction over compressively strained $\mathrm{CuAg}$ surface alloys with enhanced multi-carbon oxygenate selectivity. J. Am. Chem. Soc. 139, 15848-15857 (2017).

18. Hoang, T. T. H. et al. Nanoporous copper-silver alloys by additive-controlled electrodeposition for the selective electroreduction of $\mathrm{CO}_{2}$ to ethylene and ethanol. J. Am. Chem. Soc. 140, 5791-5797 (2018).

19. Morales-Guio, C. G. et al. Improved $\mathrm{CO}_{2}$ reduction activity towards $\mathrm{C}^{2+}$ alcohols on a tandem gold on copper electrocatalyst. Nat. Catal. 1, 764-771 (2018).

20. Zhuang, T.-T. et al. Steering post-C-C coupling selectivity enables high efficiency electroreduction of carbon dioxide to multi-carbon alcohols. Nat. Catal. 1, 421-428 (2018).

21. Zhou, Y. et al. Dopant-induced electron localization drives $\mathrm{CO}_{2}$ reduction to $\mathrm{C}_{2}$ hydrocarbons. Nat. Chem. 10, 974-980 (2018).

22. Liang, Z. Q. et al. Copper-on-nitride enhances the stable electrosynthesis of multi-carbon products from $\mathrm{CO}_{2}$. Nat. Commun. 9, 3828-3836 (2018).

23. Hahn, C. et al. Engineering $\mathrm{Cu}$ surfaces for the electrocatalytic conversion of $\mathrm{CO}_{2}$ : controlling selectivity toward oxygenates and hydrocarbons. Proc. Natl Acad. Sci. USA 114, 5918-5923 (2017).

24. Hoang, T. T. H., Ma, S., Gold, J. I., Kenis, P. J. A. \& Gewirth, A. A. Nanoporous copper films by additive-controlled electrodeposition: $\mathrm{CO}_{2}$ Reduction catalysis. ACS Catal. 7, 3313-3321 (2017).

25. Lv, J. J. et al. A highly porous copper electrocatalyst for carbon dioxide reduction. Adv. Mater. 30, 1803111-1803119 (2018).

26. Ma, S. et al. One-step electrosynthesis of ethylene and ethanol from $\mathrm{CO}_{2}$ in an alkaline electrolyzer. J. Power Sources 301, 219-228 (2016).

27. Li, Y. \& Sun, Q. Recent advances in breaking scaling relations for effective electrochemical conversion of $\mathrm{CO}_{2}$. Adv. Energy Mater. 6, 1600463-1600482 (2016).

28. Xiao, H., Cheng, T. \& Goddard, W. A. III. Atomistic mechanisms underlying selectivities in $\mathrm{C}(1)$ and $\mathrm{C}(2)$ products from electrochemical reduction of $\mathrm{CO}$ on $\mathrm{Cu}(111)$. J. Am. Chem. Soc. 139, 130-136 (2017).

29. Lum, Y., Cheng, T., Goddard, W. A. \& Ager, J. W. Electrochemical CO reduction builds solvent water into oxygenate products. J. Am. Chem. Soc. 140, 9337-9340 (2018).

30. Liu, X. et al. $\mathrm{pH}$ effects on the electrochemical reduction of $\mathrm{CO}_{(2)}$ towards $\mathrm{C}_{2}$ products on stepped copper. Nat. Commun. 10, 32-42 (2019).

31. Subbaraman, R. et al. Enhancing hydrogen evolution activity in water splitting by tailoring $\mathrm{Li}^{+}-\mathrm{Ni}(\mathrm{OH})_{2}-\mathrm{Pt}$ interfaces. Science 334, 1256-1260 (2011).

32. Dinh, C.-T. et al. Multi-site electrocatalysts for hydrogen evolution in neutral media by destabilization of water molecules. Nat. Energy 4, 107-114 (2018).

33. Subbaraman, R. et al. Trends in activity for the water electrolyser reactions on 3d M(Ni,Co,Fe,Mn) hydr(oxy)oxide catalysts. Nat. Mater. 11, 550-557 (2012).

34. Pourbaix, M. Atlas of Electrochemical Equilibria in Aqueous Solutions 2nd edn (National Association of Corrosion Engineers, 1974).

35. Ng, J. W. D. et al. Gold-supported cerium-doped $\mathrm{NiO}_{\mathrm{x}}$ catalysts for water oxidation. Nat. Energy 1, 16053-16061 (2016).

36. De Luna, P. et al. Catalyst electro-redeposition controls morphology and oxidation state for selective carbon dioxide reduction. Nat. Catal. 1, 103-110 (2018).

37. Li, J. et al. Copper adparticle enabled selective electrosynthesis of n-propanol. Nat. Commun. 9, 4614-4623 (2018).

38. Cheng, T., Xiao, H. \& Goddard, W. A. Full atomistic reaction mechanism with kinetics for $\mathrm{CO}$ reduction on $\mathrm{Cu}(100)$ from ab initio molecular dynamics freeenergy calculations at 298 K. Proc. Natl Acad. Sci. USA 114, 1795-1800 (2017).

39. Varandili, S. B. et al. Synthesis of $\mathrm{Cu} / \mathrm{CeO}_{2-\mathrm{x}}$ nanocrystalline heterodimers with interfacial active sites to promote $\mathrm{CO}_{2}$ electroreduction. ACS Catal. 9, 5035-5046 (2019).

40. Kresse, G. \& Furthmüller, J. Efficient iterative schemes for ab initio totalenergy calculations using a plane-wave basis set. Phys. Rev. B 54, 11169-11186 (1996).

41. Kresse, G. \& Furthmüller, J. Efficiency of ab-initio total energy calculations for metals and semiconductors using a plane-wave basis set. Comput. Mater. Sci. 6, 15-50 (1996).

42. Kresse, G. \& Hafner, J. Ab initio molecular dynamics for liquid metals. Phys. Rev. B 47, 558-561 (1993).

43. Kresse, G. \& Hafner, J. Ab initio molecular-dynamics simulation of the liquidmetal-amorphous-semiconductor transition in germanium. Phys. Rev. B 49, 14251-14269 (1994).

44. Blöchl, P. E. Projector augmented-wave method. Phys. Rev. B 50, 17953-17979 (1994). 
45. Kresse, G. \& Joubert, D. From ultrasoft pseudopotentials to the projector augmented-wave method. Phys. Rev. B 59, 1758-1775 (1999).

46. Perdew, J. P., Burke, K. \& Ernzerhof, M. Generalized gradient approximation made simple. Phys. Rev. Lett. 77, 3865-3868 (1996).

47. Dudarev, S. L., Botton, G. A., Savrasov, S. Y., Humphreys, C. J. \& Sutton, A. P. Electron-energy-loss spectra and the structural stability of nickel oxide: An LSDA+U study. Phys. Rev. B 57, 1505-1509 (1998).

48. Lustemberg, P. G. et al. Room-temperature activation of methane and dry reforming with $\mathrm{CO}_{2}$ on $\mathrm{Ni}-\mathrm{CeO}_{2}(111)$ surfaces: effect of $\mathrm{Ce}^{3+}$ sites and metal-support interactions on $\mathrm{C}-\mathrm{H}$ bond cleavage. ACS Catal. 12, 8184-8191 (2016).

49. Grimme, S., Antony, J., Ehrlich, S. \& Krieg, H. A consistent and accurate ab initio parametrization of density functional dispersion correction (DFT-D) for the 94 elements H-Pu. J. Chem. Phys. 132, 154104 (2010).

\section{Acknowledgements}

The authors acknowledge funding supporting from Suncor Energy, the Ontario Research Fund and the Natural Sciences and Engineering Research Council (NSERC). All DFT calculations were performed on the IBM BlueGene/Q supercomputer with support from the Southern Ontario Smart Computing Innovation Platform (SOSCIP) and Niagara supercomputer at the SciNet HPC Consortium. SOSCIP is funded by the Federal Economic Development Agency of Southern Ontario, the Province of Ontario, IBM Canada Ltd., Ontario Centres of Excellence, Mitacs, and 15 Ontario academic member institutions. SciNet is funded by the Canada Foundation for Innovation, the Government of Ontario, Ontario Research Fund - Research Excellence, and the University of Toronto. This research used synchrotron resources of the Advanced Photon Source (APS), an Office of Science User Facility operated for the U.S. Department of Energy (DOE) Office of Science by Argonne National Laboratory, and was supported by the U.S. DOE under Contract No. DE-AC02-06CH11357, and the Canadian Light Source and its funding partners. The authors thank T. P. Wu, Y. Z. Finfrock, and L. Ma for technical support at 9BM beamline of APS. J.L. acknowledges the Banting Postdoctoral Fellowships program. D.S. acknowledges the NSERC E.W.R Steacie Memorial Fellowship.

\section{Author contributions}

E.H.S. supervised the project. M.L. designed and carried out the experiments. Y.C.L. and Z.W. designed and carried out the DFT calculations. J.W., A.X., T.Z., and D.H.N. performed the XPS and XRD measurements. J.L., D.H.N., and Y.L. performed and analyzed the in situ XAS measurements. M.L. and F.L. performed and analyzed the Raman measurements. B.C. collected the STEM images and did the EDX mapping. W.L., Y.W., and X.W., collected the SEM images and did the EDX analysis. Y.H.W. prepared sputtered metal electrodes. C.T.D., D.S., and E.H.S. edited the paper. All authors discussed the results. M.L., Y.C.L., and Z.W. wrote the paper.

\section{Competing interests}

The authors declare no competing interests.

\section{Additional information}

Supplementary information is available for this paper at https://doi.org/10.1038/s41467019-13833-8.

Correspondence and requests for materials should be addressed to E.H.S.

Peer review information Nature Communications thanks William Goddard and other, anonymous, reviewers for their contributions to the peer review of this work. Peer review reports are available.

Reprints and permission information is available at http://www.nature.com/reprints

Publisher's note Springer Nature remains neutral with regard to jurisdictional claims in published maps and institutional affiliations.

Open Access This article is licensed under a Creative Commons Attribution 4.0 International License, which permits use, sharing, adaptation, distribution and reproduction in any medium or format, as long as you give appropriate credit to the original author(s) and the source, provide a link to the Creative Commons license, and indicate if changes were made. The images or other third party material in this article are included in the article's Creative Commons license, unless indicated otherwise in a credit line to the material. If material is not included in the article's Creative Commons license and your intended use is not permitted by statutory regulation or exceeds the permitted use, you will need to obtain permission directly from the copyright holder. To view a copy of this license, visit http://creativecommons.org/ licenses/by/4.0\%

(C) The Author(s) 2019 